\title{
Pengaruh Penyuluhan Keluarga Berencana terhadap Peningkatan Pengetahuan tentang Keluarga Sakinah
}

\author{
Nurfadilah Rohimah* \\ Jurusan Bimbingan dan Konseling Islam, UIN Sunan Gunung Djati, Bandung \\ *Email:nrohmab54@gmail.com
}

\begin{abstract}
ABSTRAK
Penelitian ini bertujuan untuk mengungkapkan respon mahasiswa terhadap penyuluhan keluarga berencana di Jurusan BKI, pengetahuan mahasiswa mengenai keluarga sakinah, dan pengaruh penyuluhan keluarga berencana terhadap peningkatan pengetahuan mahasiswa mengenai keluarga sakinah di jurusan BKI angkatan 2015 Fakultas Dakwah dan Komunikasi UIN Bandung. Metode penelitian yang digunakan adalah metode survey dengan pendekatan kuantitatif. Teknik pengambilan sampel yang digunakan adalah teknik purpositive sampling yakni seluruh mahasiswa Bimbingan dan Konseling Islam angkatan 2015 yang mengikuti matakuliah Penyuluhan Keluarga Berencana dan pernah mengikuti matakuliah Fiqih Keluarga Muslim. Rentang usia responden adalah 20-25 tahun dan belum menikah. Sampel yang memenuhi kriteria tersebut sebanyak 40 orang. Hasil penelitian menunjukkan respon mahasiswa terhadap penyuluhan KB sebesar 82,2 \% sangat tinggi. Pengetahuan tentang keluarga sakinah sebesar $87 \%$ sangat tinggi. H1 diterima artinya terdapat pengaruh positif penyuluhan keluarga berencana terhadap peningkatan pengetahuan tentang keluarga sakinah bagi mahasiswa BKI 2015. Adapun besar pengaruhnya sebesar 46,1\%. Besaran peningkatannya jika peningkatan pengetahuan tentang keluarga sakinah naik satu satuan maka nilai penyuluhan $\mathrm{KB}$ akan naik sebesar 0,802 dan sisa nilai 0,2 merupakan nilai peningkatan dari variabel yang tidak penulis teliti.
\end{abstract}

Kata Kunci : Penyuluhan; Keluarga Berencana; Keluarga Sakinah

\section{ABSTRACT}

This research is aimed to express student's response to birth control extension in BKI Department, student's knowledge about sakinah family, and the influence of family planning extension on student's knowledge about sakinah family in BKI Department, Faculty of Da'wah and Communication UIN Bandung, class of 2015. Survey method with quantitative approach is used in this research. The purposive sampling technique is applied with the 
participants are all the students of Islamic Counseling and Guidance class of 2015, which taken the birth control Counseling course and Fiqih Muslim Family course. The result of the research shows that the student's response to birth control extension is $82.2 \%$ very high. The knowledge of sakinah family is $87 \%$ very high. H1 accepted means there is a positive influence of birth control extension on increasing knowledge about sakinah family for student BKI 2015. The influence of magnitude that is equal to 46,1\%. The calculation is that if the increase of knowledge sakinah family rose one unit, then the value of family planning will rise by 0.802 and the remaining value of 0.2 is an increase value of the variable that is not the author carefully.

Keywords: Counseling; Birth Control; Sakinah Family

\section{PENDAHULUAN}

Program keluarga berencana menjadi salah satu program yang paling sering digalakan di Negara yang berkembang seperti Indonesia. Selain bertujuan untuk menekan laju pertumbuhan penduduk, program keluarga berencana ternyata memiliki banyak keunggulan lain yang patut untuk diketahui. Program keluarga berencana, atau sering disingkat KB, menjadi salah satu solusi yang banyak diterapkan di negara-negara dengan tingkat populasi penduduk yang tinggi. Tingkat populasi penduduk yang tinggi sendiri banyak ditemukan di negaranegara berkembang, seperti Cina, India, dan Indonesia. Permasalahan kepadatan penduduk sendiri telah menjadi masalah dunia sejak lama. Pada tahun 2013 lalu, jumlah penduduk dunia telah mencapai 7,2 milyar jiwa dan diproyeksikan akan menyentuh angka 10,9 milyar jiwa pada tahun 2100 yang akan datang (Suryanto, 2013). Jika pertumbuhan penduduk terus dibiarkan, maka akan mengakibatkan ledakan penduduk yang pada akhirnya berimplikasi pada sektor pembangunan. Beragam dampak ledakan penduduk antara lain; kurangnya ketersediaan pangan, lahan pertanian dan hutan, bencana banjir dan longsor, kemiskinan, kemacetan, polusi udara, masalah kesehatan, pendidikan, ekonomi, serta kurangnya lapangan pekerjaan sehingga angka pengangguran meningkat (BKKBN, 2015).

Hal yang sama juga akan terjadi di Indonesia. Penduduk Indonesia diperkirakan bertambah sekitar 4,5 juta jiwa per tahunnya. Badan Kependudukan dan Keluarga Berencana Nasional (BKKBN) menyebutkan bahwa berdasarkan sensus penduduk tahun 2010 diketahui bahwa 27,6\% dari jumlah penduduk Indonesia berada pada kelompok umur remaja 10-24 tahun yaitu sekitar 64 juta jiwa. Lebih lanjut BKKBN menyatakan bahwa jumlah tersebut sangat besar sehingga menjadikan remaja sebagai generasi penerus bangsa perlu dipersiapkan menjadi manusia yang sehat secara jasmani, rohani, mental dan spiritual. Namun ternyata saat ini, BKKBN menyebutkan bahwa faktanya, berbagai penelitian menunjukkan bahwa remaja mempunyai permasalahan yang sangat kompleks seiring dengan masa transisi yang dialami remaja. Selanjutnya BKKBN juga 
menyebutkan bahwa masalah yang menonjol dikalangan remaja yaitu permasalahan seputar tiga hal yang berkaitan dengan Kesehatan Reproduksi Remaja (TRIAD KRR) yakni seksualitas, Human Immunodeficiency Virus (HIV)/ AIDS serta Narkotika, Psikotropika dan Zat Adiktif (NAPZA), serta rendahnya pengetahuan remaja tentang Kesehatan Reproduksi Remaja dan median usia kawin pertama perempuan relatif masih rendah (BKKBN, 2015:1).

Menurut Malthus dalam (Robert, 2003:51) salah satu cara untuk mencegah permasalahan remaja sebagai akibat ledakan penduduk adalah dengan melakukan kontrol atau pengawasan terhadap pertumbuhan penduduk, yaitu dengan menunda usia perkawinan dan merencanakan jumlah anak. Kedua langkah tersebut diharapkan mampu mengendalikan kelahiran yang merupakan masalah pokok kependudukan (Pasrah, 2014:8). Dalam usaha mengatasi ledakan penduduk, pemerintah melalui BKKBN, melaksanakan program Keluarga Berencana (KB) sebagai salah satu upaya pengendalian penduduk. Program ini bertujuan menekan Laju Pertumbuhan Penduduk (LPP) dengan cara penggunaan alat-alat kontrasepsi. Sementara untuk menanggapi permasalahan yang muncul di kalangan remaja, BKKBN memiliki program Generasi Berencana (GenRe) yang mempromosikan program-program Keluarga Berencana sejak dini bagi kaum remaja.

Peningkatan mutu kehidupan dapat dicapai dengan berbagai cara, antara lain dengan pendidikan yang baik dan berkualitas dan penanaman nilai moral kedalam sikap dan perilaku individu. Islam mengajak manusia untuk hidup dalam naungan keluarga, karena keluarga merupakan gambaran kecil dalam kehidupan stabil yang menjadi pemenuhan keinginan manusia tanpa menghilangkan kebutuhannya. Menikah memang tidaklah sulit, tetapi membangun keluarga sakinah bukanlah sesuatu yang mudah, terlebih dahulu orang harus memiliki konsep mengenai keluarga sakinah. Al-Qur'an membangunkan sebuah keluarga sakinah dan kuat untuk membentuk suatu tatanan masyarakat yang memelihara aturan-aturan Allah Swt dalam kehidupan. Atura yang ditawarkan oleh Islam menjamin terbinanya keluarga bahagia, karena nilai kebenaran yang dikandunginya, serta keselarasannya yang ada dalam fitrah Manusia.

Hidup berumah tangga merupakan tuntutan fitrah Manusia sebagai makhluk sosial. Keluarga atau rumah tangga muslim adalah lembaga terpenting dalam kehidupan kaum muslimin umumnya dan Manhaj amal Islami khususnya. Ini semua disebabkan karena peran besar yang dimainkan oleh keluarga, yaitu mencetak dan menumbuhkan generasi masa depan, pilar penyangga bangunan umat dan perisai penyelamat bagi negara. Maka tidak berlebihan apabila dikatakan bahwa keluarga merupakan pondasi awal dari bangunan masyarakat dan bangsa. Oleh karenanya, keselamatan dan kemurnian rumah tangga adalah 
faktor penentu bagi keselamatan dan kemurnian masyarakat, serta sebagai penentu kekuatan, kekokohan, dan keselamatan dari bangunan negara. Sebuah keluarga semestinya menjadi tempat yang paling membahagiakan. Tempat ternyaman untuk melepas segala beban kepenatan. Sakinah, tenang merupakan tempat terjalinnya hubungan paling mesra. Tempat di mana ada getaran hati ayah dan bunda di dalamnya. Mawaddah, penuh cinta keluarga juga semestinya menjadi tempat yang penuh dengan hiasan kasih sayang. Ayah, ibu dan anak saling berbagi perhatian, kasih sayang, saling tolong, saling menguatkan, saling menopang, saling menasehati, saling bicara penuh kelembutan. Rahmah, penuh kasih sayang (Rosnawati, 2017: 90).

Menikah bukanlah hal yang tabu lagi dikalangan remaja masa kini. Meski BKKBN sering menggalakan penyuluhan keluarga berencana kini muncul program nikah muda juga sedang digencarkan oleh para remaja akhir-akhir ini. Hal tersebut dicetuskan dibalik nama agama karena melihat fenomena hamil diluar nikah dan gaya pacaran anak muda masa kini yang melewati batas. Tidak semua remaja memiliki kesiapan dan perencanaan yang matang untuk melakukan menikah muda. Maka dari itu, penyuluhan keluarga berencana gencar melakukan komunikasi, memberikan edukasi dan informasi untuk mencegah terjadinya nikah muda dan mengarahkan remaja untuk merencanakan masa depannya. Perencanaan itu meliputi pendidikan yang cukup, perencanaan karir yang matang, dan perencanaan pernikahan yang idela sesuai dengan usia ideal menikah yakni perempuan 21 tahun dan laki-laki 25 tahun. Selain perencanaan di atas, diaharapkan dengan menikah diusia ideal, pasangan akan memiliki kontrol emosi yang baik dan mental yang matang sehingga dapat menyelesaikan permasalahan dengan baik yang akan berdampak pada kesiapan mengasuh dan mendidik anak menjadi generasi yang lebih baik lagi dan menekan angka perceraian.

Kegiatan penyuluhan keluarga berencana di jurusan bimbingan konseling Islam, masuk sebagai salah satu matakuliah pilihan. Mahasiswa bisa memilih untuk mengikuti matakuliah tersebut atau memilih matakuliah lain yang disajikan karena terdapat dua matakuliah pilihan di semester enam. Dosen pengampu terkadang bekerja sama dengan BKKBN Kota Bandung, BKKBN Jawa Barat hingga Nasional untuk mengadakan kuliah umum bagi mahasiswa. Isu yang diangkat pun beragam dari masalah kependudukan, kesiapan Indonesia menghadapi Bonus Demografi, HIV/AIDS, Kesehatan reproduksi remaja dll. Matakuliah Penyuluhan Keluarga Berencana ini melatih mahasiswa menjadi penyuluh professional khususnya sebagai penyuluh di bidang keluarga berencana dan mampu menghadapi dan terjun langsung ke masyarakat sehingga mengetahui bagaiman tugas penyuluh keluarga berencana yang sesungguhnya. Selain itu mahasiwa juga bisa ikut berpartisipasi dalam pemilihan duta generasi berencana yang setiap tahun diadakan oleh pihak BKKBN. 
Penelitian terdahulu menunjukkan bahwa dengan pelaksanaan kegiatan penyuluhan program KB yang baik, di mana komunikasi antara penyuluh dengan PUS tercipta dengan didukung oleh materi, media, metode, dan pemilihan waktu serta tempat yang tepat dan sesuai menghasilkan dampak yang positif (Pahlupi, Suryana, \& Setiaman, 2012). Begitu pula menurut Basuki \& Soesilowati (2015) dengan adanya konseling maka terjadi transfer informasi mengenai kelebihan, kekurangan, efektivitas dan efisiensi masing-masing alat kontrasepsi antara calon akseptor dengan petugas kesehatan. Hal ini menunjukkan bahwa konseling efektif untuk meningkatkan pengetahuan dan kemantapan dalam pemilihan kontrasepsi pada calon akseptor. Sejalan dengan penelitian yang dilakukan oleh Makhdum (2017) bahwa penyuluhan KB melalui pendekatan agama berada pada kategori baik dengan presentase sebesar $47 \%$.

\section{LANDASAN TEORITIS}

Penelitian ini dilandaskan pada teori yang menjadi pembahasan inti. Pembahasan inti dari penelitina ini adalah tentang pengaruh penyuluhan keluarga berencana (KB) untuk meningkatkan pengetahuan tentang keluarga sakinah bagi remaja. Teori yang melandasi penelitian ini adalah teori Bebaviorisme dengan menggunakan teori ini, peneliti dapat mengukur dan mengamati perkembangan perilaku yang dihasilkan oleh respon mahasiswa terhadap rangsanga. Tanggapan terhadap rangsangan dapat diperkuat dengan umpan balik positif atau negatif terhadap perilaku kondisi yang diinginkan. Ciri dari teori ini adalah mengutamakan unsur-unsur dan bagian kecil, bersifat mekanistis, menekankan peran lingkungan, mementingkan pembentukan reaksi atau respon, menekankan pentingnya latihan, mementingkan mekanisme hasil belajar, mementingkan peran kemampuan dan hasil belajar yang diperoleh adalah munculnya perilaku yang diinginkan.

Penyuluhan dalam arti umum berarti ilmu sosial yang mempelajari sistem dan perubahan pada individu serta masyarakat agar dapat terwujud perubahan yang lebih sesuai dengan apa yang diharapkan. Penyuluhan adalah proses perubahan sosial, ekonomi dan politik untuk memberdayakan dan memperkuat kemampuan semua stakeholders, melalui proses belajar bersama yang partisipatip, agar terjadi perubahan perilaku pada diri setiap individu dan masyarakatnya untuk mengelola kegiatan yang semakin produktif dan efisien, demi terwujudnya kehidupan yang baik, dan semakin sejahtera secara berkelanjutan (Banuharli, 2011:7).

Keluarga berencana merupakan usaha untuk mengukur jumlah anak dan jarak kelahiran anak yang diinginkan. Maka dari itu, Pemerintah mencanangkan program atau cara untuk mengatur dan menunda kehamilan (Sulityawati A, 
2013:15). Kewenangan dan urusan BKKBN tidak hanya terbatas pada masalah yang berhubungan dengan pembangunan kependudukan dan Keluarga Berencana namun juga menyangkut masalah yang berhubungan dengan keluarga sejahtera.

Program Keluarga Berencana menurut UU no.52 Tahun 2009 tentang perkembangan Kependudukan dan Pembangunan Keluarga adalah upaya mengatur kelahiran anak, jarak dan usia ideal melahirkan, mengatur kehamilan, melalui promosi, perlindungan dan bantuan sesuai dengan hak reproduksi untuk mewujudkan keluarga yang berkualitas. Sedangkan menurut UU no 10 tahun 1992 (tentang perkembangan kependudukan dan pembangunan keluarga sejahtera) adalah upaya peningkatan kepedulian dan peran serta masyarakat melalui pendewasaan usia perkawinan (PUP), pengaturan kelahiran, pembinaan ketahanan keluarga, peningkatan kesejahteraan keluarga kecil, bahagia, dan sejahtera (Barat, 2012:45-46).

Dalam al-qur'an dicantumkan beberapa ayat yang berkaitan dengan keluarga berencana, diantaranya dalam Surat An-Nisa:9:

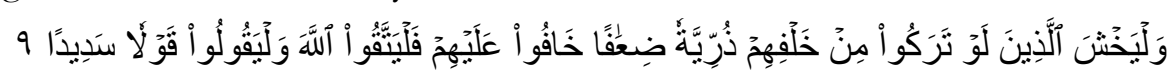

"Dan hendaklah takut kepada Allah orang-orang yang seandainya meninggalkan dibelakang mereka anak-anak yang lemah, yang mereka khawatir terhadap (kesejahteraan) mereka. Oleh sebab itu hendaklah mereka bertakwa kepada Allah dan hendaklah mereka mengucapkan perkataan yang benar". (RI, 2014: 78)

Ayat-ayat al-quran di atas menunjukan bahwa Islam mendukung adanya keluarga berencana karena dalam QS. An-Nissa ayat 9 dinyatakan bahwa "hendaklah takut kepada Allah orang-orang yang seandainya meninggalkan dibelakang mereka anak-anak yang lemah". Anak lemah yang dimaksud adalah generasi penerus yang lemah agama, ilmu, pengetahuan sehingga KB menjadi upaya agar mewujudkan keluarga yang sakinah. Pandangan Hukum Islam tentang Keluarga Berencana, secara prinsipil dapat diterima oleh Islam, bahkan $\mathrm{KB}$ dengan maksud menciptakan keluarga sejahtera yang berkualitas dan melahirkan keturunan yang tangguh sangat sejalan dengan tujuan syari at Islam yaitu mewujudkan kemaslahatan bagi umatnya. Selain itu, KB juga memiliki sejumlah manfaat yang dapat mencegah timbulnya kemudlaratan. Bila dilihat dari fungsi dan manfaat $\mathrm{KB}$, maka tidak diragukan lagi kebolehan KB dalam Islam.

Kata keluarga dilihat dari segi etimologi, maka berasal dari dua kata yakni kawula dan warga. Kawula berarti hamba dan warga berarti anggota. Kedua kata ini mempunyai kesatuan makna dan arti. Jadi pengertian keluarga ialah suatu kesatuan (unit) di mana anggota-anggotanyamengabdikan diri kepada 
kepentingan dan tujuan unit tersebut. Menurut Undang-Undang Kependudukan dan Keluarga Sejahtera Pasal 1 ayat 10, keluarga adalah unit terkecil dalam masyarakat yang terdiri dari suami-isteri, atau suami-isteri dan anak-anaknya atau ayah dan anak-anaknya, atau ibu dan anak-anaknya (agama, 2014:11).

Keluarga sakinah dapat diartikan sebagai system kelurga yang berlandaskan keimana dan ketaqwaan kepada Allah, beramal shaleh untuk meningkatkan potensi semua anggota, dan beramal shaleh untuk keluarga-keluarga lain disekitarnya, serta berwasiat atau berkomunikasi dengan cara bimbingan yang haq, kesabaran dan penuh dengan kasih sayang (Willis, 2017:30).

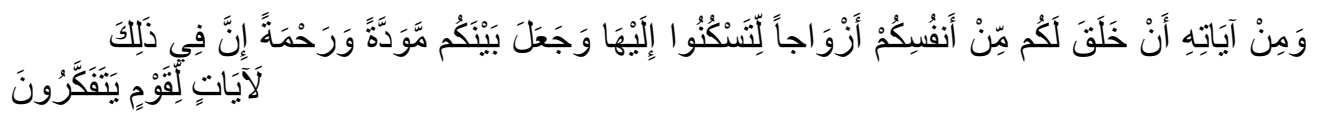

Artinya : "Dan di antara tanda-tsaya kekuasaan-Nya ialah Dia menciptakan untukmu isteri-isteri dari jenismu sendiri, supaya kamu cenderung dan merasa tenteram kepadanya, dan dijadikan-Nya diantaramu rasa kasih dan sayang. Sesungguhnya pada yang demikian itu benar-benar terdapat tanda-tsaya bagi kaum yang berfikir." (RI, 2014: 406).

Arti Sakinah adalah tenteram, tenang, sedangkan Mawaddah adalah kecintaan dan Rahmah adalah rasa sayangatau kasihan. Ibn Katsir di dalam Tafsir Al-Quranul 'Adzim menjelaskan, bahwa ayat ini menandaskan tentang di antara tsaya kebesaran Allah yang menunjukkan keagungan dan kesempurnaan kekuasaan-Nya adalah Allah menciptakan wanita yang menjadi pasangan pria, agar tumbuh ketenteraman karenanya. Melalui tali pernikahan, pasangan suami isteri saling condong kepada sebagian lainnya, yang sebelumnya tidak saling mengenal, tidak saling mencintai dan mengasihi. Karena itulah, maka rasa kasih dan sayang yang tertanam sebagai fitrah Allah swt di antara pasangan suami-isteri akan bertambah besar, seiring dengan bertambahnya kebaikan pada keduanya. Sebaliknya, akan berkurang seiring menurunnya kebaikan pada keduanya.

Dalam sebuah riwayat Aswad ra mengatakan bahwa: saya telah bertanya kepada Aisyah ra bahwa apa yang Rasulullah saw biasa lakukan di rumah. Beliau berkata "beliau senantiasa sibuk dalam pengkhidmatan terhadap keluarga beliau dan apabila tiba waktu shalat maka beliau pergi untuk melakukan shalat (Bukhari kitabul adzan). Kita semua mafhum bahwa Rasulullah adalah sosok yang paling sibuk dan paling tekun dalam beribadah, tetapi beliau lihatlah bagaimana cara beliau menjalani bahtera rumah tangga kita akan dibuat berdecak kagum. Rasulullah saw begitu cekatan dalam membantu istri-istrinya dalam kehidupan sehari-hari. Rasulullah saw bersabda, orang yang terbaik diantara kalian adalah orang yang paling baik perlakuannya terhadap keluarga atau istrinya dan beliau bersabda, saya dari antara kalian adalah orang yang memperlakukan paling baik 
terhadap keluarganya (Tirmidzi Kitaabulnaaqib).(Satriah, 2017, hal. 34)

\section{HASIL DAN PEMBAHASAN}

Penelitian ini dilakukan di Universitas Islam Negeri Sunan Gunung Djati, Fakultas Dakwah dan Komunikasi, Jurusan Bimbingan Konseling Islam Jl. A.H Nasution No 105 Cipadung, Kota Bandung. Alasan penulis menentukan lokasi di penelitian Kampus UIN Bandung khususnya di jurusan Bimbingan Konseling Islam karena jurusan tersebut memiliki kegiatan penyuluhan keluarga berencana melalui matakuliah pilihan penyuluh KB. Diadakannya matakuliah tersebut untuk meningkatkan profesionalitas mahasiswa sebagai penyuluh terutama penyuluh $\mathrm{kb}$ serta melatih mahasiswa untuk merencanakan kehidupan dan masa depannya serta mengatasi dan mengendalikan ledakan penduduk. Penelitian ini ditujukan pada mahasiswa Jurusan Bimbingan dan Konseling Islam angkatan 2015, Fakultas Dakwah dan Komunikasi, Universitas Islam Negeri Sunan Gunung Djati Bandung yang terletak di Jl. A.H. Nasution No. 105 Cipadung, Kota Bandung.

Visi Jurusan Bimbingan dan Konseling Islam adalah menjadi Program Studi unggulan dan kompetitif tingkat Nasional di Bidang Bimbingan dan Konseling Islam pada Tahun 2025. Misi Jurusan Bimbingan dan Konseling Islam adalah menyelenggarakan pendidikan dan pengajaran untuk menghasilkan tenaga profesional di bidang Bimbingan dan Konseling Islam, menyelenggarakan penelitian dan publikasi ilmiah guna mengembangkan ilmu dan aplikasi bidang Bimbingan dan Konseling Islam, menyelenggarakan layanan pengabdian pada masyarakat yang profesional dengan penerapan inovasi bidang Bimbingan dan Konseling Islam.

Tujuan Jurusan Bimbingan dan Konseling Islam adalah menghasilkan lulusan yang berakhlak karimah dan memiliki standar kompetensi akademik di bidang Bimbingan dan Konseling Islam, menghasilkan penelitian dan publikasi bermutu dalam mengembangkan ilmu dan aplikasi bidang bimbingan dan konseling Islam, menghasilkan inovasi layanan pengabdian pada masayarakat yang profesional di bidang Bimbingan Dan Konseling Islam.

\section{Respon Mahasiswa terhadap Penyuluhan Keluarga Berencana Di Jurusan BKI}

Penyuluhan sebagai proses perubahan social, dipandang sebagi suatu bentuk pendidikan untuk orang dewasa. Penyuluhan merupakan keterlibatan seseorang untuk melakukan komunikasi informasi secara sadar dengan tujuan membantu sesamanya memberikan pendapat sehingga bisa membuat keputusan yang benar (Prayitno, 2009:94). Penyuluhan adalah proses perubahan perilaku di kalangan masyarakat agar mereka tahu, mau dan mampu melakukan perubahan demi 
tercapainya peningkatan produksi, pendapat atau keuntungan dan perbaikan kesejahteraannya. Tujuan penyuluhan adalah membantu sesama memberikan pendapat sehingga bisa membuat keputusan yang benar dan untuk melakukan komunikasi informasi secara sadar.

Program KB bertujuan untuk membentuk keluarga kecil sesuai dengan kekuatan sosial ekonomi suatu keluarga dengan cara pengaturan kelahiran anak agar diperoleh suatu keluarga bahagia dan sejahtera yang dapat memenuhi kebutuhan hidupnya (Sulityawati A, 2013:18). Tujuan program KB lainnya yaitu untuk menurunkan angka kelahiran yang bermakna, untuk mencapai tujuan tersebut maka diadakan kebijakaan yang dikategorikan dalam tiga fase (menjarangkan, menunda, dan menghentikan) maksud dari kebijakaan tersebut yaitu untuk menyelamatkan ibu dan anak akibat melahirkan pada usia muda, jarak kelahiran yang terlalu dekat dan melahirkan pada usia tua (Hartanto, 2012:35).

Keluarga berencana menghendaki keluarga yang berkualitas, Islam memuji orang yang memiliki kualitas dan sangat dicintai Allah swt. Rasulullah bersabda:

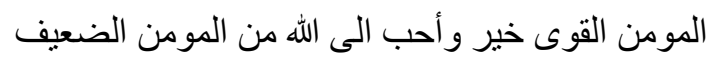

"seorang mu'min yang kuat itu lebih baik dan lebih dicintai Alah swt dari pada seorang mu'min yang lemah."

Istilah keluarga berencana dimaksudkan untuk menjarangkan kehamilan, dan Islam menyebutnya dalam bentuk lain yaitu menyapihnya selama dua tahun, kedua istilah ini mengandung maksud untuk mengatur kehamilan. Allah swt berfirman dalam Q.S Luqman: 14

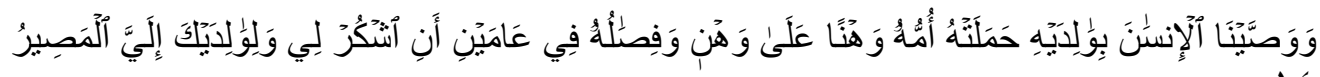

"Dan Kami perintahkan kepada manusia (berbuat baik) kepada dua orang ibubapaknya; ibunya telah mengandungnya dalam keadaan lemah yang bertambahtambah, dan menyapihnya dalam dua tahun. Bersyukurlah kepada-Ku dan kepada dua orang ibu bapakmu, hanya kepada-Kulah kembalimu.” (RI, 2014: 412)

Penggunaan alat kontrasepsi dalam pandangan Islam adalah sebagai alat pengatur keturunan, dan itu di perbolehkan sedangkan untuk membatasi kelahiran itu di haramkan. Islam memperbolehkan memakai alat kontrasepsi modern untuk mengatur kehamilan secara temporer (sementara) dan bukan permanen. Pada masa Rasulullah saw, dilakukan "azal" sebagai alat kontrasepsi alami. Untuk MOW/MOP dulu memang dianggap permanen tapi kini sudah di temukan "rekanalisasi" atau penyambungan ulang. Untuk alat kontrasepsi 


\section{N. Rohimah}

lainnya hukumnya jelas boleh. Majlis Ulama Indonesia pun telah memfatwakan keharaman penggunaan KB sterilisasi ini pada tahun 1983 dengan alasan sterilisasi bisa mengakibatkan kemandulan tetap (Barat, 2012:64-69).

Untuk mendapatkan hasil yang akurat dalam mengukur respon mahasiswa mengenai Penyuluhan Keluarga Berencana di jurusan Bimbingan dan Konseling Islam angkatan 2015 Fakultas Dakwah dan Komunikasi UIN Bandung, penulis membagikan kuisioner kepada mahasiswa yang mengikuti matakuliah penyuluh keluarga berencana dan pernah mengikuti matakuliah fiqih keluarga muslim. Dalam penentuan kategorisasi skala perhitungan hasil kuisioner yang telah diisi oleh setiap mahasiswa BKI, jumlah skor ideal dihitung menggunakan SPSS.2.0. untuk interpretasi kategorisasi skala perhitungan nilai variabel $\mathrm{X}$ (penyuluhan keluarga berencana) penulis menggunakan skla sebagai berikut:

Tabel 1. Kategorisasi Skala Perhitungan

\begin{tabular}{lll}
\hline \multicolumn{1}{c}{ Rentang Skor } & \multicolumn{1}{c}{ Presentase skor } & \multicolumn{1}{c}{ Kategorisasi } \\
\hline $161-200$ & $81-100 \%$ & Sangat Tinggi \\
$121-160$ & $61-80 \%$ & Tinggi \\
$81-120$ & $41-60 \%$ & Cukup Tinggi \\
$41-80$ & $21-40 \%$ & Rendah \\
$0-40$ & $0-20 \%$ & Sangat Rendah \\
\hline
\end{tabular}

Berdasarkan kuisioner yang telah dibagikan kepada seluruh responden yang berjumlah 40 orang, pada kuisioner variabel $\mathrm{X}$ penulis memberikan pernyataan yang berkaitan dengan penyuluhan keluarga berencana disesuaikan dengan aspek dan indikator keluarga berencana. Namun, untuk penomoran kuisioner penulis membaginya secara acak menyesuaikan dengan keterkaitan antara pernyataan yang satu dan yang lainnya. Penulis akan membahas pernyataan setiap kuisioner dengan hasil sebagai berikut. Agar lebih jelas mengenai nilai penyuluhan keluarga berencana di jurusan BKI angkatan 2015, dapat dilihat dari tabel berikut:

Tabel 2. Kriteria penilaian variabel X (penyuluhan keluarga berencana)

\begin{tabular}{|c|c|c|c|}
\hline Pernyataan & $\begin{array}{l}\text { Jumlah } \\
\text { Kumulat } \\
\text { if }\end{array}$ & $\begin{array}{c}\text { Nilai } \\
(\%)\end{array}$ & Kriteria \\
\hline $\begin{array}{l}\text { Jika saya menikah sebelum usia } 20 \text { tahun, } \\
\text { sayaakan menggunakan alat kontrasepsi utuk } \\
\text { merencanakan kehamilan anak pertama dan } \\
\text { menjarangkan kehamilan berikutnya }\end{array}$ & 148 & $74 \%$ & Tinggi \\
\hline
\end{tabular}


Saya akan mengikuti kegiatan penyuluhan tentang kesehatan reproduksi

164

Jika saya menikah sebelum usia 20 tahun, saya akan menunda kehamilan

Setelah saya menikah dan memiliki anak jarak ideal usia dari anak pertama ke anak kedua adalah 5 tahun

Jika saya memasuki usia 35 tahun, saya akan mengakhiri masa kehamilan

Jika saya perempuan, saya berencana menikah pada usia minimal 20 tahun dan jika saya laki-laki saya berencana menikah pada usia minimal 25 tahun

Jika pasangan saya mengajak menikah ketika usia saya belum mencapai 20 tahun bagi perempuan dan 25 tahun bagi laki-laki, saya akan menunda kelahiran anak pertama

Saya akan selalu siap untuk membantu anggota keluarga jika mereka membutuhkan

Saya sudah mendapatkan informasi mengenai HIV/Aids dari tenaga ahli

Orangtua saya memberikan informasi cara menghindari penyakit menular seksual dengan menjauhi free sex

Orangtua saya menyarankan untuk mengikuti kegiatan penyuluhan narkoba

Orangtua ikut mengarahkan saya dalam merencanakan masa depan saya seperti karir, percintaan atau pendidikan

Jika saya mempunyai permasalahan saya akan mendiskusikan permasalah tersebut denga orangtua

Orangtua selalu mendukung setiap kegiatan positif yang saya lakukan

Saya selalu mendiskusikan kegiatan saya dengan orangtua

Saya suka menceritakan kegiatan sehari-hari dengan orangtua

Rata-rata 
Berdasarkan hasil analisis yang telah diuraikan diperoleh hasil bahwa respon mahasiswa terhadap penyuluhan keluarga berencana di jurusan BKI cukup tinggi. Hal ini dibuktikan dengan respon mahasiswa terhadap rangsangan atau materi mengenai program keluarga berencana cukup tinggi. Dari 16 soal mengenai penyuluhan keluarga berencana yang diberikan kepada 40 responden rata-rata nilai yang diperoleh adalah $82,2 \%$ dan masuk kedalam kategori sangat tinggi.

\section{Pengetahuan Mahasiswa Mengenai Keluarga Sakinah}

Di antara ragam pranata sosial, keluarga merupakan bentuk pranata yang fundamental dan paling purba. Keberadaannya terbentuk dalam rentang historis paling lama sejak zaman primitive dengan berbagai variasi bentuk. Terbangun sebagai kebutuhan eksistensial manusia sebagai unit terkecil tempat kebutuhan biologis, ekonomi, kelestarian eksistensi, serta kebutuhan psikhis dipenuhi. Alokasi hak dan sumber daya di antara anggota keluarga dilakukan dalam sebuah mekanisme yang terjalin sangat rapih. Di dalam pranata keluarga terdapat norma bagaimana hak dan kewajiban ditetapkan di antara keluarga berikut bagaimana harta peninggalan dari anggota keluarga yang meninggal dibagi di antara mereka.

Norma fiqh yang menentukan keabsahan perkawinan ada 4 (empat): akad, calon pengantin, saksi, dan wali bagi mempelai perempuan. Keempat norma di atas secara umum sangat dipatuhi secara legal-normatif. Akan tetapi terkait dengan norma terakhir, wali nikah, dalam beberapa kasus diberlakukan cukup longgar seperti dalam implementasi semangat dari peran perwalian.Sedangkan implementasi norma-norma lain seperti yang terkait dengan hubungan hak dan kewajiban suami istri, pengasuhan dan pendidikan anak, serta soal pembagian harta penginggalan ketika salahsatu anggota keluarga ada yang meninggal meskipun tidak sejelas dan sekuat implementasi norma pertama berlangsung cukup massif. Hal itu dapat dilihat dari kenyataan dari refleksi komunikasi mereka bahwa mereka melaksanakan kewajiban keluarga sesuai dengan agama.(Haris, 2008: 151-152)

Keluarga menurut konsep Islam adalah satu kesatuan hubungan antara seorang laki-laki dan seorang perempuan yang dilakukan dengan dilalui akad nikah menurut ajaran Islam (Faqih, 2001:11). Al-quran menjelaskan bahwa inti dari keluarga itu ialah adanya ikatan pernikahan antara dua jenis (laki-laki dan perempuan) untuk mencapai suatu tujuan, yaitu ketentraman dalam kerangka sakinah, mawaddah warahmah. Jadi pengertian keluarga itu sendiri ialah satuan terkecil dalam sistem sosial masyarakat umat Islam yang tidak saja tempat ketentraman lahir batin, cinta dan kasih sayang, tetapi juga sebagai suatu 
perjanjian berat dan kokoh yang harus dipertanggungjawabkan. Keluarga ini terbentuk sejak terealisasikan akan pernikahan. Karena itu, lembaga keluarga minimal anggotanya terdiri dari seorang suami dan sorang isteri.

Keluarga sakinah bukan hanya khayalan, namun sesuatu yang nyata dan bisa di wujudkan dalam kehidupan sehari-hari. Berikut beberapa ciri keluarga sakinah menurut (Satriah, 2017, hal. 40-44) berdiri di atas pondasi keimanan yang kokoh, menunaikan misi ibadah dalam kehidupan, mentaati ajaran agama, saling mencintai dan menyayangi, saling menjaga dan menguatkan dalam kebaikan, saling memberikan yang terbaik untuk pasangan, mudah menyelesaikan masalah, membagi peran berkeadilan, kompak mendidik anak dan berkontribusi untuk kebaikan masyarakat.

Memiliki keluarga yang utuh adalah dambaan setiap orang yang berada dalam suatu pernikahan. Untuk mendapatkan keluarga dan rumah tangga yang utuh, diperlukan adanya cara membina keluarga dengan sakinah, mawadah dan warohmah. Menikah adalah salah satu tindakan untuk mengikuti sunnah Rasul. Karena itulah orang yang menikah harus menjaga pernikahannya dengan baik agar kehidupan rumah tangganya menjadi tenteram dan langgeng. Berikut perisapan-persiapan yang harus dilakukan seseorang yang hendak membangun Keluarga Sakinah yakni persiapan fikriyah (konsepsional dan intelektual), persiapan fisik (jasadiab), persiapan rubiyyah, persiapan psikologis, memilih calon istri yang baik dan memilih calon suami yang baik.

Untuk mendapatkan hasil yang akurat dalam mengukur pengetahuan mahasiswa mengenai keluarga sakinah di jurusan Bimbingan dan Konseling Islam angkatan 2015 Fakultas Dakwah dan Komunikasi UIN Bandungpenulis akan membahas pernyataan setiap kuisioner dengan hasil sebagai berikut. Agar lebih jelas mengenai nilai pengetahuan tentang keluarga sakinah di jurusan BKI angkatan 2015, dapat dilihat dari tabel berikut:

Tabel 3. Kriteria penilaian variabel Y (Pengetahuan tentang keluarga sakinah)

\begin{tabular}{llcc}
\hline \multicolumn{1}{c}{ Pernyataan } & $\begin{array}{c}\text { Jumlah } \\
\text { Kumulatif }\end{array}$ & $\begin{array}{c}\text { Nilai } \\
\mathbf{( \% )}\end{array}$ & Kriteria \\
\hline $\begin{array}{l}\text { Saya akan mengikuti pelatihan calon pengantin } \\
\text { atau konseling pra nikah sebelum menikah }\end{array}$ & 188 & $94 \%$ & $\begin{array}{l}\text { Sangat } \\
\text { Tinggi }\end{array}$ \\
$\begin{array}{l}\text { Jika saya sudah menikah, saya akan menjalin } \\
\text { komunikasi yang baik dengan pasangan } \\
\text { sehingga terwujudnya rasa cinta kasih sayang }\end{array}$ & 185 & $92,5 \%$ & $\begin{array}{l}\text { Sangat } \\
\text { Tinggi }\end{array}$ \\
$\begin{array}{l}\text { yang tulus dan ikhlas } \\
\text { Saya sependapat dengan istilah silih asah, silih }\end{array}$ & 178 & $89 \%$ & Sangat \\
\hline
\end{tabular}


asih, silih asuh sesuai dengan budaya sunda dan

Tinggi

menerapkannya dalam mendidik anak

Setelah saya menikah, saya akan menjadikan

keluarga sebagai tempat pertama untuk

185

mengenalkan ajaran agama terhadap anak saya

Saya siap menghadapi berbagai persoalan yang akan datang dalam perkawinan

180

Jika saya sudah menikah dan memiliki anak, saya akan menegur anak saya dengan cara yang baik dan penuh kasih sayang

Saya akan melakukan shalat istikhoroh dalam menentukan pasangan hidup

Jika saya memiliki anak, saya akan

menanamkan pendidikan agama sebagai dasar bagi kehidupannya

Jika saya melahirkan, saya ingin ditangani oleh tenaga ahli (dokter atau bidan) agar dapat menjaga keselamatan bayi yang akan dilahirkan

Saya rutin memeriksakan kesehatan reproduksi

Sebelum menikah saya sudah mempersiapkan berbagai kebutuhan untuk memenuhi kebutuhan ekonomi dan berkeluarga

$$
\begin{array}{rr}
81,5 \% & \text { Sangat } \\
& \text { Tinggi }
\end{array}
$$

Agar dapat memenuhi kebutuhan hidup dalam berkeluarga, saya berkeinginan untuk dapat membantu suami dengan bekerja

Menurut saya laki-laki dan perempuan memiliki hak dan kewajiban yang sama dalam mengurus rumah tangga

Jika saya sudah menikah dan memiliki anak, saya akan menyembunyikan pertengkaran saya di depan anak seolah-olah tidak terjadi apa-apa

Saya ikut berpartisipasi aktif dalam kegiatan masyarakat

Pengetahuan tentang keluarga sakinah merupakan hasil dari tanggapan mahasiswa terhadap rangsangan yang diperkuat dengan umpan balik positif terhadap perilaku yang diinginkan. Hal tersebut dibuktikan dengan pemahaman 
dan kesiapan mahasiswa mengenai keluarga sakinah yang cukup tinggi. Dari 16 soal mengenai pengetahuan tentang keluarga sakinah yang di ajukan kepada 40 responden, rata-rata nilai yang diperoleh adalah $87 \%$ dan masuk kedalam kategori sangat tinggi.

\section{Pengaruh Penyuluhan Keluarga Berencan terhadap Peningkatan Pengetahuan Mahasiswa Mengenai Keluarga Sakinah}

Pengaruh penyuluhan keluarga berencana terhadap peningkatan pengetahuan tentang keluarga sakinah dapat dilihat dari adanya keterkaitan antara dua variable $\mathrm{X}$ (Penyuluhan Keluarga Berencana) dan variable Y (Keluarga Sakinah). Pengaruh dari kedua variabel tersebut dapat dilihat dari penjelasan dibawah ini.

Uji validitas digunakan untuk mengetahui kelayakan butir-butir dalam suatu pertanyaan dalam mendefinisikan suatu variable. Uji validitas sebaiknya dilakukan pada setiap butir pertanyaan di uji validitasnya. Uji validitas dilakukan kepada non sample sebelum kepada sample sesungguhnya dengan jumlah responden sebanyak 40 orang, maka nilai $r$ tabel dapat diperoleh melalui table $r$ product moment pearson. Hasil $\mathrm{r}$ hitung akan dibandingkan dengan $\mathrm{r}$ table $\mathrm{df}=\mathrm{n}-2$ sebagai $\operatorname{sig} \alpha$. Jika $r$ table $<\mathrm{r}$ hitung maka valid.

Tabel 4. Item-Total Statistics

\begin{tabular}{lllll}
\hline No & $\begin{array}{c}\text { Scale Mean if } \\
\text { Item Deleted }\end{array}$ & $\begin{array}{c}\text { Scale Variance } \\
\text { if Item } \\
\text { Deleted }\end{array}$ & $\begin{array}{c}\text { Corrected } \\
\text { Item-Total } \\
\text { Correlation }\end{array}$ & $\begin{array}{c}\text { Cronbach's } \\
\text { Alpha if Item } \\
\text { Deleted }\end{array}$ \\
\hline X1 & 61,0000 & 58,154 &, 636 &, 793 \\
X2 & 60,6000 & 67,272 &, 312 &, 815 \\
X3 & 60,3250 & 65,917 &, 584 &, 808 \\
X4 & 60,5500 & 65,126 &, 369 &, 812 \\
X5 & 61,1250 & 60,369 &, 481 &, 804 \\
X6 & 60,7250 & 61,948 &, 399 &, 810 \\
X7 & 61,6000 & 59,887 &, 589 &, 797 \\
X8 & 60,8500 & 64,285 &, 483 &, 807 \\
X9 & 60,6750 & 61,251 &, 473 &, 805 \\
X10 & 60,4250 & 61,584 &, 495 &, 804 \\
X14 & 60,9500 & 64,151 &, 336 &, 814 \\
X16 & 61,5250 & 57,076 &, 540 &, 800 \\
X18 & 61,3500 & 61,926 &, 381 &, 812 \\
\hline
\end{tabular}


N. Rohimah

\begin{tabular}{lllcc}
\hline X19 & 61,3500 & 64,746 &, 316 &, 815 \\
X20 & 61,3250 & 64,174 &, 282 &, 818 \\
X21 & 61,3750 & 64,240 &, 292 &, 817 \\
\hline
\end{tabular}

Sumber data : output SPSS yang diolah 2018

$\mathrm{R}_{\text {tabel }}$ yang digunakan $=0,2638$, karena nilai $\mathrm{R}_{\text {hitung }}>\mathrm{R}_{\text {tabel }}$ maka seluruh item pernyataan variabel $\mathrm{X}$ dinyatakan valid.

Tabel 5. Reliability Statistics

\begin{tabular}{ll}
$\begin{array}{c}\text { Cronbach's } \\
\text { Alpha }\end{array}$ & N of Items \\
\hline 818 & 16 \\
\hline
\end{tabular}

Sumber data : output SPSS yang diolah 2018

Dapat dilihat pada nilai Crobach's Alpha dengan aturan kriteria uji :Cronbach's Alpa> 0,70 maka kontruk pertanyaan yang merupakan dimensi variable $\mathrm{X}$ adalah reliable.

Tabel 6. Item-Total Statistics

\begin{tabular}{ccccc}
\hline No & $\begin{array}{c}\text { Scale Mean if } \\
\text { Item Deleted }\end{array}$ & $\begin{array}{c}\text { Scale } \\
\text { Variance if } \\
\text { Item Deleted }\end{array}$ & $\begin{array}{c}\text { Corrected } \\
\text { Item-Total } \\
\text { Correlation }\end{array}$ & $\begin{array}{c}\text { Cronbach's } \\
\text { Alpha if Item } \\
\text { Deleted }\end{array}$ \\
\hline Y11 & 69,7750 & 90,487 &, 304 &, 921 \\
Y12 & 69,3500 & 90,849 &, 535 &, 913 \\
Y13 & 69,1000 & 95,015 &, 330 &, 917 \\
Y15 & 70,2500 & 87,577 &, 493 &, 914 \\
Y17 & 69,3750 & 90,292 &, 385 &, 917 \\
Y22 & 69,1750 & 81,840 &, 845 &, 903 \\
Y23 & 69,7000 & 84,472 &, 708 &, 907 \\
Y24 & 69,3750 & 85,676 &, 789 &, 906 \\
Y25 & 69,3000 & 88,062 &, 648 &, 910 \\
Y26 & 69,3500 & 89,003 &, 532 &, 912 \\
Y27 & 69,1750 & 86,610 &, 699 &, 908 \\
Y28 & 69,4250 & 81,071 &, 823 &, 903 \\
\hline
\end{tabular}




\begin{tabular}{lllll}
\hline Y29 & 69,1000 & 93,015 &, 557 &, 913 \\
Y30 & 69,4500 & 88,972 &, 627 &, 910 \\
Y31 & 69,7750 & 86,128 &, 580 &, 911 \\
Y32 & 69,7000 & 86,677 &, 618 &, 910 \\
Y33 & 69,4250 & 81,071 &, 823 &, 903 \\
\hline
\end{tabular}

Sumber data : output SPSS yang diolah 2018

$R_{\text {tabel }}$ yang digunakan $=0,2638$, karena nilai $R_{\text {hitung }}>R_{\text {tabel }}$ maka seluruh item pernyataan variabel $\mathrm{Y}$ dinyatakan valid.

\begin{tabular}{cc} 
Tabel 7. Reliability Statis \\
$\begin{array}{c}\text { Cronbach's } \\
\text { Alpha }\end{array}$ & $\begin{array}{c}\text { N of } \\
\text { Items }\end{array}$ \\
\hline, 916 & 17 \\
\hline
\end{tabular}

Sumber data : output SPSS yang diolah 2018

Dapat dilihat pada nilai Crobach's Alpha dengan aturan kriteria uji : Cronbach's Alpa > 0,70 maka kontruk pertanyaan yang merupakan dimensi variable $\mathrm{Y}$ adalah reliable.

Tabel 8. One-Sample Kolmogorov-Smirnov Test

\begin{tabular}{|c|c|c|}
\hline & & $\begin{array}{c}\text { Unstandar } \\
\text { dized } \\
\text { Residual }\end{array}$ \\
\hline \multicolumn{2}{|l|}{$\mathrm{N}$} & 40 \\
\hline \multirow{3}{*}{$\begin{array}{l}\text { Normal } \\
\text { Parametersa,b }\end{array}$} & Mean & 0E-7 \\
\hline & $\begin{array}{l}\text { Std. } \\
\text { Deviation }\end{array}$ & 7,27751723 \\
\hline & Absolute & ,212 \\
\hline \multirow{2}{*}{$\begin{array}{l}\text { Most Extreme } \\
\text { Differences }\end{array}$} & Positive & ,153 \\
\hline & Negative &,- 212 \\
\hline \multicolumn{2}{|c|}{ Kolmogorov-Smirnov Z } & 1,340 \\
\hline \multicolumn{2}{|c|}{ Asymp. Sig. (2-tailed) } & ,055 \\
\hline \multicolumn{3}{|c|}{ a. Test distribution is Normal. } \\
\hline \multicolumn{3}{|c|}{ b. Calculated from data. } \\
\hline
\end{tabular}


N. Rohimah

Sumber data: output SPSS yang diolah 2018

Dari hasil output SPSS diperoleh $\mathrm{Pv}(0,055)>0,05$ maka $\mathrm{H}_{0}$ diterima, maka nilai residual tersebut normal atau dapat disimpulkan bahwa uji normalitas untuk penelitian tersebut terpenuhi.

Tabel 10. ANOVA Table

\begin{tabular}{|c|c|c|c|c|c|c|c|}
\hline & & & $\begin{array}{l}\text { Sumof } \\
\text { Squares }\end{array}$ & df & $\begin{array}{c}\text { Mean } \\
\text { Square }\end{array}$ & $\mathbf{F}$ & Sig. \\
\hline \multirow{5}{*}{$\begin{array}{l}\text { KELUARGA } \\
\text { SAKINAH * } \\
\text { PENYULUH KB }\end{array}$} & \multirow{3}{*}{$\begin{array}{l}\text { Between } \\
\text { Groups }\end{array}$} & $\begin{array}{l}\text { (Combine } \\
\text { d) }\end{array}$ & 3623,900 & 20 & 181,195 & 16,672 & ,000 \\
\hline & & Linearity & 1764,872 & 1 & 1764,872 & 162,385 &, 000 \\
\hline & & $\begin{array}{l}\text { Deviation } \\
\text { from } \\
\text { Linearity }\end{array}$ & 1859,028 & 19 & 97,844 & 9,003 & ,000 \\
\hline & \multicolumn{2}{|c|}{ Within Groups } & 206,500 & 19 & 10,868 & & \\
\hline & \multicolumn{2}{|l|}{ Total } & 3830,400 & 39 & & & \\
\hline
\end{tabular}

Sumber data : output SPSS yang diolah 2018

Karena $\mathrm{Pv}(0,000)<0,05$ maka $\mathrm{H}_{0}$ DITOLAK sehingga Model regresi linier sederhana dapat digunakan dalam memprediksi peningkatan pengetahuan tentang keluarga sakinah yang dipengaruhi oleh penyuluhan keluarga berencana.

Tabel 11. Coefficients ${ }^{a}$

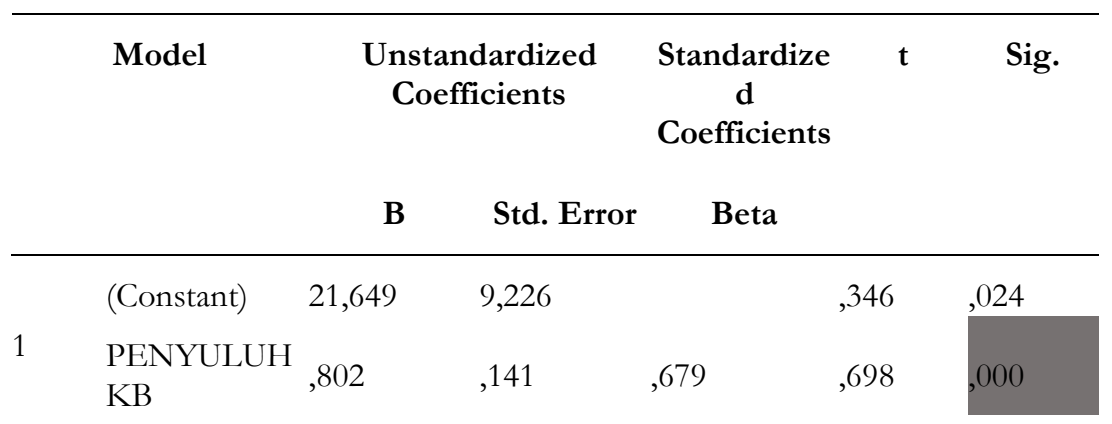

a. Dependent Variable: KELUARGA SAKINAH

Sumber data: output SPSS yang diolah 2018

Dari tabel Coefficients yang dipaparkan dapat diketahui ada tidaknya pengaruh penyuluhan keluarga berencana terhadap peningkatan pengetahuan tentang keluarga sakinah bagi mahasiswa BKI 2015. Karena $\mathrm{Pv}<0,05 \mathrm{maka}_{0}$ DITOLAK sehingga Terdapat Pengaruh Penyuluhan Keluarga Berencana 
terhadap Peningkatan Pengetahuan Tentang Keluarga Sakinah Bagi Mahasiswa BKI 2015.

Tabel 1. Model Summary ${ }^{\mathrm{b}}$

\begin{tabular}{lllll}
\hline Model & R & R Square & $\begin{array}{c}\text { Adjusted R } \\
\text { Square }\end{array}$ & $\begin{array}{c}\text { Std. Error of the } \\
\text { Estimate }\end{array}$ \\
\hline $1 \quad, 679^{a}$ & $, 461 \quad, 447$ & 7,373 \\
a. Predictors: (Constant), PENYULUH KB & \\
b. Dependent Variable: KELUARGA SAKINAH & \\
\hline
\end{tabular}

Sumber data : output SPSS yang diolah 2018

Besar pengaruh penyuluhan keluarga berencana terhadap peningkatan pengetahuan tentang keluarga sakinah. $\mathrm{r}^{2}=0,461$ sehingga $\mathrm{KD}$ yang didapat adalah 46,1\%. Hal ini menunjukkan bahwa persentase penyuluhan keluarga berencana terhadap peningkatan pengetahuan tentang keluarga sakinah adalah 46,1\% dan sisanya dipengaruhi oleh variabel lain selain penyuluhan keluarga berencana atau diluar variable yang diteliti.

Tabel 2. Coefficients ${ }^{a}$

\begin{tabular}{|c|c|c|c|c|c|c|}
\hline \multirow[t]{2}{*}{ Mode } & & \multicolumn{2}{|c|}{$\begin{array}{l}\text { Unstandardized } \\
\text { Coefficients }\end{array}$} & \multirow{2}{*}{$\begin{array}{l}\text { Standardized } \\
\text { Coefficients } \\
\text { Beta }\end{array}$} & & \multirow[t]{2}{*}{ Sig. } \\
\hline & & B & Std. Error & & & \\
\hline & (Constant) & 21,649 & 9,226 & & 2,346 & ,024 \\
\hline 1 & $\begin{array}{l}\text { PENYULUH } \\
\text { KB }\end{array}$ & 802 & ,141 & ,679 & 5,698 & ,000 \\
\hline
\end{tabular}

a. Dependent Variable: KELUARGA SAKINAH

Sumber data: output SPSS yang diolah 2018

Besar peningkatan pengetahuan tentang keluarga sakinah yang dipengaruhi oleh penyuluhan keluarga berencana. Koefesien regresi di notasikan dengan B, artinya bila tidak ada perubahan pada variabel $x$ (Penyuluhan $K B)(x=0)$ maka variabel tidak memiliki penambahan nilai atau nilainya constant yaitu $\mathrm{x}=21,649$. Jika x mengalami peningkatan sebesar 1 satuan, maka variabel y meningkat sebesar 0,802 . Sisa nilai 0,2 merupakan nilai peningkatan dari variabel yang tidak penulis teliti.

$$
\mathrm{Y}=21,649+0,802 \mathrm{X}
$$

Konstanta $(\mathrm{a})=21,649$ Artinya : Apabila pengaruh penyuluhan keluarga 
N. Rohimah

berencana sama dengan nol ( tidak ada perubahan), maka peningkatan pengetahuan tentang keluarga sakinah sebesar 0,802.Koefisien Regresi Penyuluhan $\mathrm{KB}(\mathrm{b})=0,802$ Artinya : Koefisien regresi postif ( searah ) sebesar 0,802. Jika penyuluhan KB meningkat 1 satuan, maka peningkatan pengetahuan meningkat sebesar 0,802 yang berarti jika penyuluhan $\mathrm{KB}$ naik sebesar 0,802 maka peningkatan pengetahuan tentang keluarga sakinah sebesar 0,802. (Sujarweni, 2015:149).

\section{PENUTUP}

Berdasarkan hasil penelitian yang telah dilakukan maka dapat disimpulkan bahwaRespon mahasiswa terhadap penyuluhan keluarga berencana di jurusan BKI cukup tinggi. Hal ini dibuktikan dengan respon mahasiswa terhadap rangsangan atau materi mengenai program keluarga berencana cukup tinggi. Hal tersebut menunjukkan bahwa responden mengetahui, memahami serta memiliki kesiapan dalam merencanakan kehidupan berkeluarga. Dari 16 soal yang diberikan, jumlah kumulatif rata-rata adalah 20 dengan nilai presentasi yang diperoleh sebesar 82,2\% dan masuk kedalam kategori sangat tinggi.

Pengetahuan mahasiswa mengenai keluarga sakinah cukup tinggi. Hal tersebut dibuktikan oleh data penyebaran angket yang menunjukkan bahwa responden lebih banyak memilih pernyataan setuju dan sangat setuju. Hal itu menunjukkan bahwa responden memahami, mengetahui serta memiliki kesiapan dalam merencakan dan membangun keluarga sakinah. Dari data yang didapatkan jumlah kumulatif rata-rata adalah 23 dengan nilai presentasi sebesar $87 \%$ dan masuk kategori cukup tinggi.

Dari hasil penelitian mengenai pengaruh penyuluhan keluarga berencana terhadap peningkatan pengetahuan tentang keluarga sakinah dengan pengambilan sample melalui teknik purposive sampling maka diambil 40 sample. Dari hasil uji validitas dengan $r_{\text {tabel }}$ yang digunakan adalah 0,2638, diperoleh nilai $\mathrm{R}$ hitung $>\mathrm{R}$ tabel maka semua item pertanyaan valid. Hasil reliabilitas nilai Cronbach's Alpha variabel $\mathrm{x}=0,818>0,7$ sedangkan nilai Cronbach's Alpha variabel $y=0,916>0,7$ maka semua kontruk pernyataan adalah reliabel. Setelah dilakukan uji normalitas dan linieritas diperoleh hasil bahwa H1 diterima artinya Terdapat pengaruh positif penyuluhan keluarga berencana terhadap peningkatan pengetahuan tentang keluarga sakinah bagi mahasiswa BKI 2015. Adapun besar pengaruh dari nilai koefisien determinasi (R Squer) sebesar 46,1\%. Koefisien regresi variabel penyuluhan keluarga berencana sebesar 0,802 artinya, jika $\mathrm{x}$ mengalami peningkatan sebesar satu satuan, maka variabel y meningkat sebesar 0,802 . Sisa nilai 0,2 merupakan nilai peningkatan dari variabel yang tidak penulis teliti.

Rekomendasi yang dapat penulis berikan bagi mahasiswa dalam 
pandangan masyarakat dianggap mampu menguasai segala bidang dan tahu mengenai berbagai hal. Mahasiswa diharapkan aktif dan menjadi contoh dalam menerapkan program keluarga berencana tersebut dalam kehidupan sehari-hari, dan mampu merencanakan kehidupannya sendiri ke arah yang lebih baik melalui program keluarga berencana ini. Oleh karena itu, mahasiswa harus menjadi sosok yang siap dibutuhkan dan mampu mengerjakan banyak hal. Mahasiwa harus dapat terus menyempurnakan pengetahuan sehingga dapat melaksanakan amanah masyarakat, menyalurkan ilmu yang didapatkan agar bisa menjadi manfaat. Mahasiswa harus peka terhadap lingkungan, mahasiswa harus bisa hadir menjadi sumber informasi dan solusi bagi banyak orang dan bukannya menjadi masalah yang hanya menjadi beban bagi masyarakat.

Bagi penyuluh $\mathrm{KB}$ agar terus berinovasi dalam menyampaikan program keluarga berencan agar lebih menarik sehingga meningkatkan rasa ingin tahu mahasiswa lebih dalam lagi. Dibutuhkan pengembangan dan kerjasama lebih lanjut dalam mengembangkan program ini terutama memperkuat landasan agama agar mahasiswa sebagai bagian dari masyarakat tidak ragu menerapkan program ini dalam kehidupan sehari-hari.

Bagi penelitian selanjutnya bagi mahasiswa atau pembaca sekalian yang berminat untuk meneliti penyuluhan keluarga berencana atau mengenai keluarga sakinah, agar dapat mengembangkan penelitiannya, baik dari segi jumlah sample yang diteliti, teori yang digunakan atau faktor pengaruh lain yang peneliti tidak teliti menjadi salah satu faktor yang mungkin lebih menarik untuk diteliti.

\section{DAFTAR PUSTAKA}

Agama, D. (2014). Tuntunan Pendidikan Kehidupan Berkeluarga. Jakarta: Depag Bekerjasama dengan BKKBN.

Banuharli, I. (2011). Materi Kuliah Dasar-Dasar Penyuluban . Yogyakarta.

Barat, T. P. (2012). Program Kependudukan dan Keluarga Berencana. Bandung: Perwakilan Badan Kependudukan dan Keluarga Berencana Nasional Provinsi Jawa Barat.

Basuki, D \& Soesilowati, R. (2015). Pengaruh Pengetahuan Mengenai Program Kb Terhadap Kemantapan Pemilihan Alat Kontrasepsi Di Rsia Aprillia Cilacap dalam Sainteks 12(2) 08-18

BKKBN. (2015, Maret 25). Diambil kembali dari BKKBN Jabar: http://jabar.bkkbn.go.id/_layouts/mobile/dis pform.aspx?List=8c526a76-8b8844fe-8f81-

BKKBN. (2015, Maret 4). Pedoman Pengelolaan Pusat Informasi dan Konseling Remaja dan Mahasiswa (PIK Remaja/Mahasiswa). Diambil kembali dari http://ceria.bkkbn.go.id/index.php/co 
N. Rohimah

mponent/jdownloads/finish/26materi-panduan/3-pedomanpengelolaanpik-remaja-danmahasiswa/0?Itemid $=0$.

Faqih, A. R. (2011). Bimbingan dan Konseling dalam Islam. Yogyakarta: UII Press.

Haris, I. A. (2008). Pranata Keluarga Muslim dalam Sistem Kekerabatan Parental Sunda. Ilmu Dakwah: Academic Journal for Homiletic Studies Vol. 4 No. 11 Januari-Juni 2008, 150-176.

Hartanto, H. (2012). Keluarga Berencana dan Kontrasepsi. Jakarta: Pustaka Sinar Harapan.

Makhdum, H. H. (2017). Penyuluhan Keluarga Berencana melalui Pendekatan Agama Terhadap Akseptor KB dalam Irsyad: Jurnal Bimbingan, Penyuluban, Konseling, dan Psikoterapi Islam 5(2) 221-240

Pahlupi, R., Suryana, A., Setiaman, A. (2012). Hubungan antara Kegiatan Penyuluhan Program Keluarga Berencana (KB) dengan Perubahan Sikap Penduduk Kabupaten Garut dalam eJournal Mahasiswa Universitas Padjadjaran 1(1) 1-18.

Pasrah. (2014). Efektifitas Program Keluarga Berencana dalam Menekan laju Pertumbuhan Penduduk di Kota Pekanbaru. Jom Fekon, Vol 1 No 2, 8.

Prayitno, E. A. (2009). Dasar-dasar Bimbingan dan Konseling. Jakarta: PT. Rineka Cipta.

RI, K. A. (2014). Al Jamil (AL-Qur'an Tajwid Warna, Terjemahan Per Kata, Terjemahan Inggris). Bekasi: Cipta Bagus Segara.

Robert, T. M. (2003). Ensiklopedi Indonesia . Dalam M. Subri, Ekonomi Sumber Daya Manusia dalam Perspektif Pembangunan. Jakarta : PT Raja Grafindo.

Rosnawati, D. (2017). Mewujudkan Keluarga Sakinah, Mawaddah Wa Rahmah. Lampung: Redaksi Remaja Islam Hebat.

Satriah, L. (2017). Bimbingan Konseling Keluarga . Bandung : CV. Mimbar Pustaka. Sujarweni, V. W. (2015). SPSS untuk Penelitian . Yogyakarta: Pustaka Baru Press. Sulityawati A, N. E. (2013). Asuhan Kebidanan pada Ibu bersalin. Jakarta: Salemba Medika.

Suryanto. (2013, Maret 25). Penduduk Dunia Capai 72 Miliar Jiwa pada Juli nanti. Diambil kembali dari http://www.antaranews.com/berita/380092/ penduduk-dunia-capai-72-miliarjiwa-pada-juli-nanti 